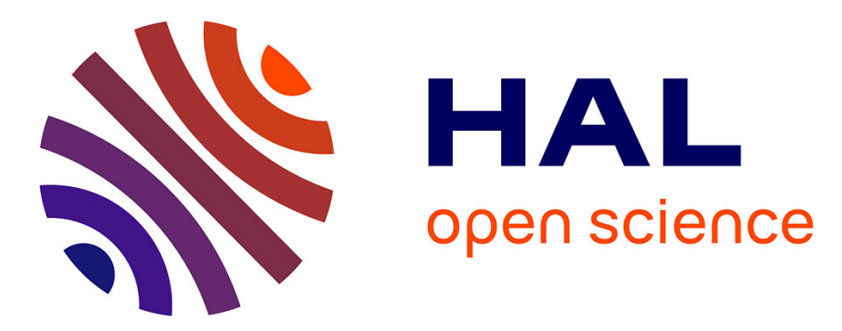

\title{
Identification of the parent bodies of micrometeorites with high-precision oxygen isotope ratios
}

Clément Suavet, Anne Alexandre, Ian A Franchi, Jérôme Gattacceca, Corinne Sonzogni, Richard Greenwood, Luigi Folco, Pierre Rochette

\section{To cite this version:}

Clément Suavet, Anne Alexandre, Ian A Franchi, Jérôme Gattacceca, Corinne Sonzogni, et al.. Identification of the parent bodies of micrometeorites with high-precision oxygen isotope ratios. Earth and Planetary Science Letters, 2010, 293 (3-4), pp.313 - 320. 10.1016/j.epsl.2010.02.046 . hal-01909569

\section{HAL Id: hal-01909569 \\ https://hal.science/hal-01909569}

Submitted on 14 Dec 2018

HAL is a multi-disciplinary open access archive for the deposit and dissemination of scientific research documents, whether they are published or not. The documents may come from teaching and research institutions in France or abroad, or from public or private research centers.
L'archive ouverte pluridisciplinaire HAL, est destinée au dépôt et à la diffusion de documents scientifiques de niveau recherche, publiés ou non, émanant des établissements d'enseignement et de recherche français ou étrangers, des laboratoires publics ou privés. 


\title{
Identification of the parent bodies of micrometeorites with high-precision oxygen isotope ratios
}

\author{
Clément Suavet $^{\mathrm{a}, *}$, Anne Alexandre ${ }^{\mathrm{a}}$, Ian A. Franchi ${ }^{\mathrm{b}}$, Jérôme Gattacceca ${ }^{\mathrm{a}}$, Corinne Sonzogni ${ }^{\mathrm{a}}$, \\ Richard C. Greenwood ${ }^{\mathrm{b}}$, Luigi Folco ${ }^{\mathrm{c}}$, Pierre Rochette ${ }^{\mathrm{a}}$ \\ a CEREGE, Aix-Marseille Université, CNRS, Europôle Méditerranéen de l'Arbois, PB-80, 13545 Aix-en-Provence cedex 04, France \\ b PSSRI, Open University, Milton Keynes, United Kingdom

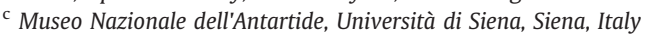

\section{A R T I C L E I N F O}

\section{Article history:}

Received 19 October 2009

Received in revised form 21 February 2010

Accepted 26 February 2010

Available online 30 March 2010

Editor: R.W. Carlson

\section{Keywords:}

micrometeorites

cosmic spherules

laser fluorination

parent bodies

carbonaceous chondrites

ordinary chondrites

\begin{abstract}
A B S T R A C T
Oxygen isotopic compositions allow identification of potential parent bodies of extraterrestrial materials. We measured oxygen isotope ratios of 33 large (diameter $>500 \mu \mathrm{m}$ ) silicate melted micrometeorites (cosmic spherules) from Antarctica, using IR-laser fluorination coupled with mass spectrometry. It is the first time that this high-precision method is used on individual micrometeorites. The selected micrometeorites are representative of the influx of extraterrestrial materials to the Earth. Our results show that most micrometeorites are related to carbonaceous chondrites, which is consistent with previous studies. However, $20-50 \%$ of them seem to be related to $\mathrm{CO} / \mathrm{CV}$ carbonaceous chondrites, whereas $\mathrm{CM} / \mathrm{CR}$ carbonaceous chondrites were thought to be the main source for micrometeorites. Furthermore, $30 \%$ of measured samples have oxygen isotope ratios lying above the terrestrial fractionation line, which relates them to ordinary chondrites or other, as yet, unsampled parent bodies.
\end{abstract}

(c) 2010 Elsevier B.V. All rights reserved.

\section{Introduction}

Micrometeorites are extraterrestrial particles smaller than about $2 \mathrm{~mm}$ collected on the Earth's surface. Based on petrographic and chemical investigation of small unmelted micrometeorites (diameter $\sim 150-250 \mu \mathrm{m}$ ), previous studies (Engrand and Maurette, 1998) have concluded that $99 \%$ of them come from carbonaceous, possibly cometary parent bodies (CM/CR related), although evidence for ordinary chondrite-related micrometeorites was recently put forward (Genge, 2008; Rochette et al., 2008). This argument has generated the belief that micrometeorites sample different objects from those sampled by macroscopic meteorites, which has been explained invoking friable parent bodies that would produce small particles upon collision rather than macroscopic fragments of rock. Subsequent ion probe oxygen isotopic analyses, mostly on melted micrometeorites (cosmic spherules: CSs) (Engrand et al., 2005; Yada et al., 2005, Taylor et al., 2005), have supported this argument as most samples had oxygen isotope ratios below the terrestrial fractionation line (TFL), except for a few samples that had ratios on the TFL within

\footnotetext{
* Corresponding author.

E-mail address: suavet@cerege.fr (C. Suavet).
}

analytical uncertainties. The typical analytical uncertainties of these ion probe analyses $\left( \pm 1-2.75 \%\right.$ on $\delta^{18} \mathrm{O}, \pm 0.7-1.7 \%$ on $\delta^{17} \mathrm{O}$, and $\pm 0.6-1.7 \%$ on $\Delta^{17} \mathrm{O}$ for individual analyses (Engrand et al., 2005; Yada et al., 2005), including the statistical uncertainty associated with the measurement of the sample as well as the uncertainty associated with the instrumental fractionation correction derived from repeated analyses of the standard mineral), make it difficult to resolve signatures indicating a potential ordinary chondrite parent body $\left(\Delta^{17} 0 \approx 0.5-1.5 \%\right.$ ) from terrestrial values. Consequently, the nearTFL values were interpreted as terrestrial contamination of carbonaceous chondrite material. IR-laser fluorination coupled with mass spectrometry (IRMS) has a much better precision, by one to two orders of magnitude: the reproducibility on quartz standards at CEREGE (Aix-en-Provence, France) is $\pm 0.15 \%$ for $\delta^{18} \mathrm{O}(n=76)$ (Alexandre et al., 2006), $\pm 0.11 \%$ ond $\pm 0.034 \%$ for $\delta^{17} \mathrm{O}$ and $\Delta^{17} \mathrm{O}$, respectively $(n=37)$; and at the Open University (Milton Keynes, United Kingdom) the reproducibility is $\pm 0.08 \%$ o and $\pm 0.04 \%$ 。 for $\delta^{18} \mathrm{O}$ and $\delta^{17} \mathrm{O}$, respectively (measured on obsidian standard, $n=31$ ), and $\pm 0.024 \%$ ofor $\Delta^{17} \mathrm{O}$ (measured on terrestrial whole rocks and mineral separates, $n=47$ ) (Miller et al., 1999). Measurements of $\delta^{18} 0$ are possible on masses as small as $0.3 \mathrm{mg}$ at CEREGE (Crespin et al., 2008), and $0.2 \mathrm{mg}$ at Open University (Greenwood et al., 2007), although such capability still limits analyses to the largest micrometeorites. The discovery of micrometeorites in the Transantarctic Mountains 
(Rochette et al., 2008) - in traps that collected micrometeorites by direct infall for hundreds of thousands of years (Folco et al., 2008, 2009) - made available hundreds of CSs with a sufficient mass to allow IRMS. Furthermore, this essentially unbiased collection (Suavet et al. 2009a) is representative of the influx of extraterrestrial materials to the Earth. In this study, we performed oxygen isotope measurements of 33 large (diameter $>500 \mu \mathrm{m}$ ) silicate ("stony") CSs from the Transantarctic Mountains collection using IRMS at CEREGE and Open University.

\section{Materials and methods}

\subsection{Samples}

Thirty-three silicate cosmic spherules (CSs) from the Transantarctic Mountains collection were selected for this study. Their masses range from $262 \mu \mathrm{g}$ to $877 \mu \mathrm{g}$ after the weathered rim was leached out using diluted $\mathrm{HCl}$ for most of the samples. Backscattered electron images of the samples were taken at CEREGE (Aix-en-Provence, France) with a scanning electron microscope (SEM, Hitachi S-3000N) using a $30 \mathrm{kV}$ accelerating voltage. SEM images (Fig. 1) allowed one to distinguish between barred olivine (BO, $23 \mathrm{CSs}$ ), porphyritic olivine (PO, 3 CSs) and glassy (7 CSs) textures (Genge et al., 2008). The distribution by types of the studied samples is similar to that of large collections (e.g. Taylor et al., 2000), assuming that cryptocrystalline and $\mathrm{BO}$ classes are merged.

\subsection{Magnetic measurements}

A magnetic characterization of the selected CSs was performed prior to the oxygen isotope measurements. Hysteresis parameters saturation magnetization $M_{\mathrm{s}}$ and saturation remanent magnetization $M_{\mathrm{rs}}$ - were measured at CEREGE with a Princeton Measurements Corporation Vibrating Sample Magnetometer (VSM) with a peak field of $0.5 \mathrm{~T}$ (noise level of $\sim 10^{-9} \mathrm{~A} \mathrm{~m}^{2}$ ). The remanent coercive field $B_{\mathrm{cr}}$ was determined by DC backfield demagnetization of the saturation remanent magnetization using the VSM.

\subsection{Oxygen isotope measurements}

Measurements of $\delta^{18} \mathrm{O}$ and $\delta^{17} \mathrm{O}$ were carried out on 28 spherules at the Stable Isotopes Laboratory of CEREGE. Molecular oxygen was extracted using the IRMS technique (Alexandre et al., 2006; Crespin et al., 2008) and the three oxygen isotopic composition was measured with a dual-inlet mass spectrometer DeltaPlus, Thermo-Finnigan. The gas $\left(\mathrm{O}_{2}\right)$ was passed through a $-114^{\circ} \mathrm{C}$ slush to refreeze potential interfering gases before being sent to the mass spectrometer. In order to get sufficient $34 / 32$ and $33 / 32$ signals $(2-3 \mathrm{~V}$ ), the oxygen from $<0.3 \mathrm{mg}$ standards and all CSs samples was concentrated in the mass spectrometer in an auto-cooled $800 \mu \mathrm{l}$ microvolume filled with silica gel and directly connected to the dual-inlet system. $\delta^{18} \mathrm{O}$ and $\delta^{17} \mathrm{O}$ values of the reference gas were fixed through the analysis of NBS28 ( $\delta^{18} \mathrm{O}=9.60 \%$ 。 (Gröning, 2004), $\delta^{17} \mathrm{O}=4.99 \%$ 。). The oxygen isotope results are expressed in \% Vs. V-SMOW. Measured $\delta^{18} \mathrm{O}$ and $\delta^{17} \mathrm{O}$ values of the samples were corrected on a daily basis using a $1.5 \mathrm{mg}$ quartz laboratory standard "Boulangé" $\left(\delta^{18} \mathrm{O}=16.36 \%\right.$ (Alexandre et al., 2006), $\delta^{17} \mathrm{O}=8.507 \%$, and $\Delta^{17} \mathrm{O}=0.006 \%$ ). During the analyzing period, replicate analyses of $1.5 \mathrm{mg}$ NBS28 $\left(\delta^{18} \mathrm{O}=9.59 \pm 0.26 \%\right.$, $\left.\delta^{17} \mathrm{O}=4.98 \pm 0.16 \%, \Delta^{17} \mathrm{O}=-0.004 \pm 0.055 \%, n=11\right)$, San Carlos olivine $\left(\delta^{18} \mathrm{O}=5.39 \pm 0.40 \%\right.$, $\delta^{17} \mathrm{O}=2.78 \pm 0.20 \%$ 。, $\Delta^{17} \mathrm{O}=-0.026 \pm$ $0.032 \%, n=22)$ and UWG-2 (Valley et al., 1995$)\left(\delta^{18} \mathrm{O}=5.69 \pm 0.18 \%\right.$, $\delta^{17} \mathrm{O}=2.96 \pm 0.11 \%$, $\left.\Delta^{17} \mathrm{O}=-0.004 \pm 0.055 \%, n=8\right)$ were made.

The relatively large scatter observed for $\delta^{18} \mathrm{O}$ and $\delta^{17} \mathrm{O}$ for SC olivine compared to NBS28 and UWG-2 is probably attributable to the heterogeneity of our San Carlos "standard" prepared from a number of millimetric crystals with possibly different oxygen isotope composi-
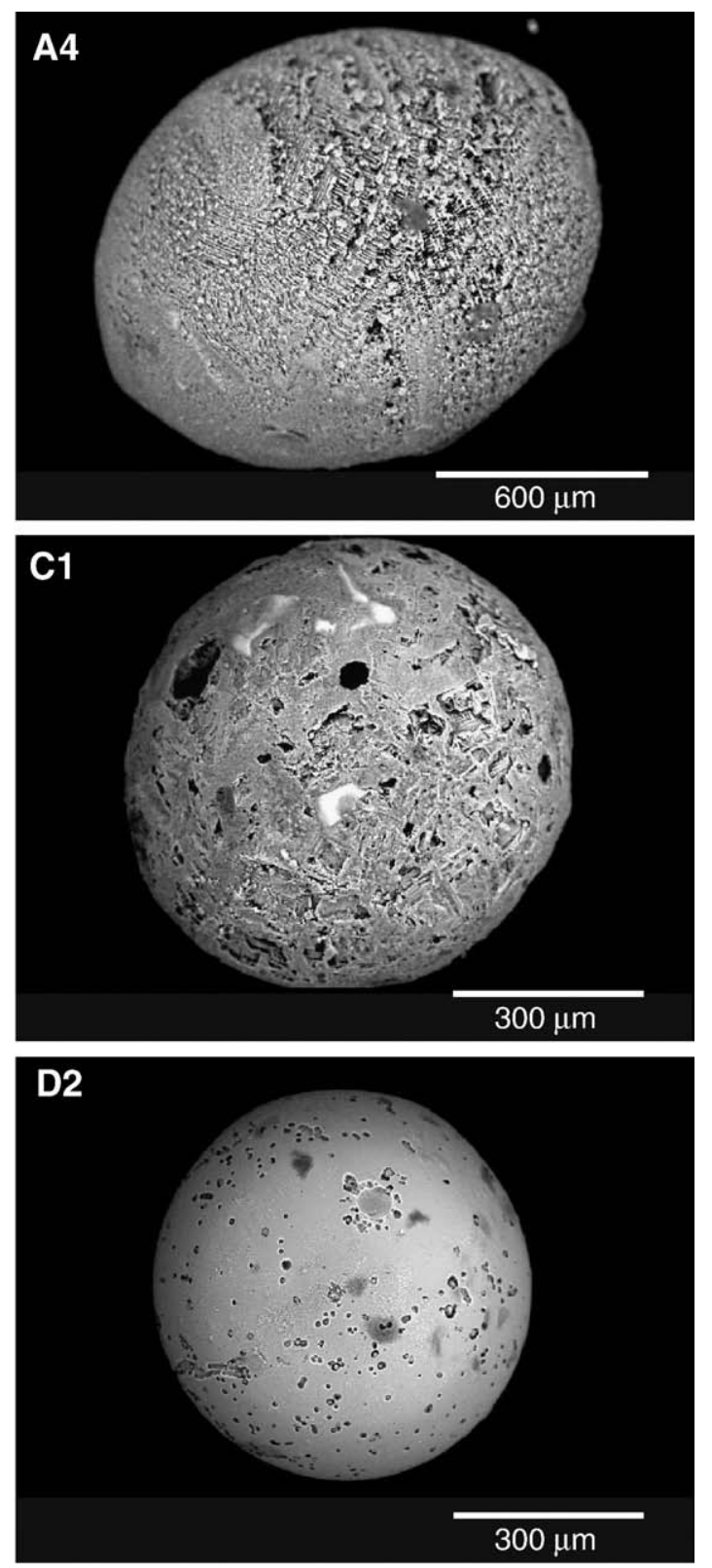

Fig. 1. Backscattered electron images of cosmic spherules A4 (barred olivine), C1 (porphyritic olivine) and D2 (glassy).

tion, as suggested by the scatter observed for the different San Carlos olivine standards used in Mattey and Macpherson (1993), Eiler et al. (1995), Rumble et al. (1997), Jabeen et al. (1998), Franchi et al. (1999), and Kusakabe et al. (2004).

Measurements made on microsamples (0.2-0.7 mg) of San Carlos olivine using the mass spectrometer-cooled microvolume (Fig. 2) show a systematic offset from the larger samples values for $\delta^{18} \mathrm{O}, \delta^{17} \mathrm{O}$ and $\Delta^{17} \mathrm{O}\left(-0.27 \pm 0.14 \%\right.$ 。 for $\delta^{18} \mathrm{O},-0.33 \pm 0.09 \%$ for $\delta^{17} \mathrm{O}$, and $-0.189 \pm 0.052 \%$ for $\left.\Delta^{17} \mathrm{O}, n=9\right)$. A similar offset was also observed when the microvolume was used to analyze quartz standard "Boulangé" $>0.25 \mathrm{mg}$ samples $\left(-0.1 \pm 0.1 \%\right.$ for $\left.\Delta^{17} \mathrm{O}, n=31\right)$, and $<0.25 \mathrm{mg}$ samples $\left(-0.16 \pm 0.05 \%\right.$ ofor $\left.\Delta^{17} \mathrm{O}, n=19\right)$. While the origin of this offset is unknown, it does not appear to be sample specific and therefore a small correction based on the systematic offsets for San Carlos olivine was made for CS samples measured at CEREGE: $+0.27 \%$ for $\delta^{18} \mathrm{O},+0.33 \%$ for $\delta^{17} \mathrm{O}$, and $+0.189 \%$ for $\Delta^{17} \mathrm{O}$. The uncertainty on the value of the offset is included in the analytical uncertainties. Five more $\mathrm{BO}$ and $\mathrm{PO}$ spherules were measured at the Open University 

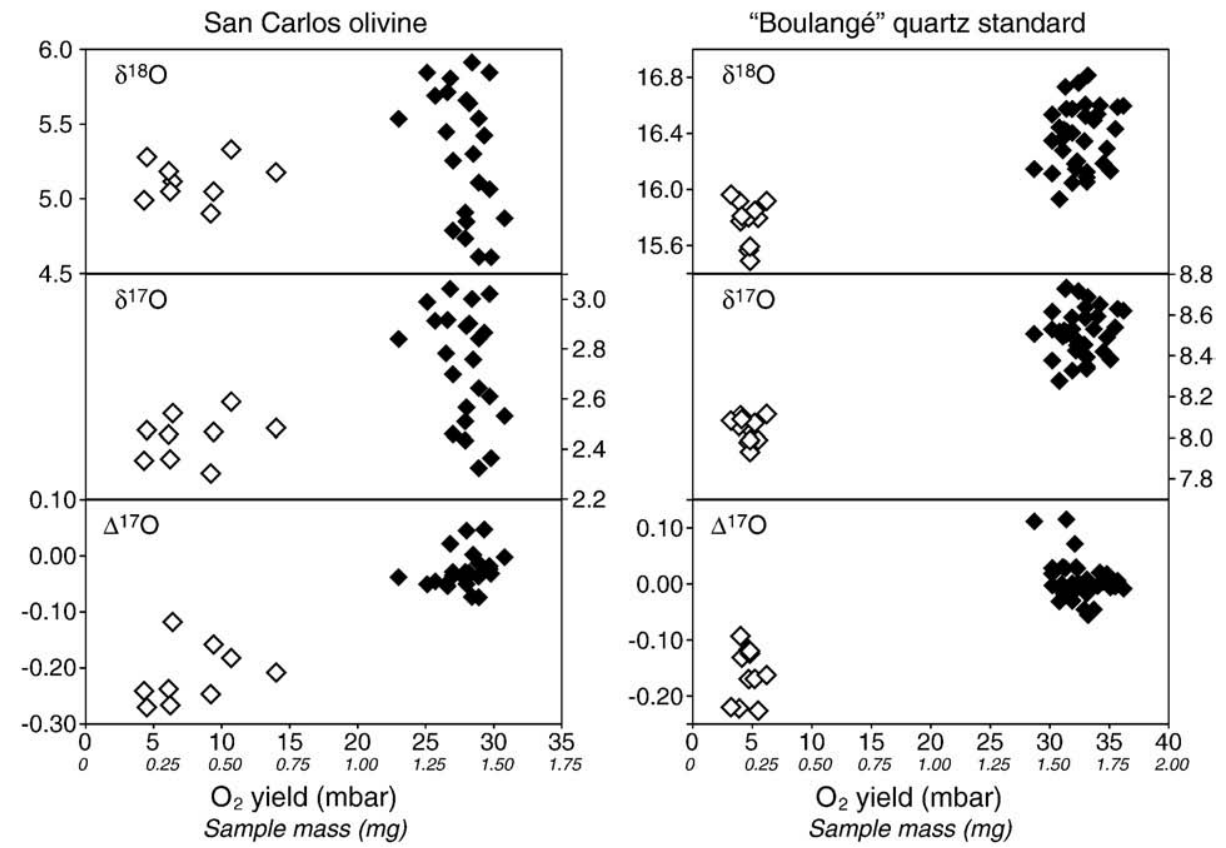

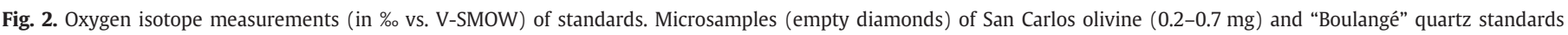

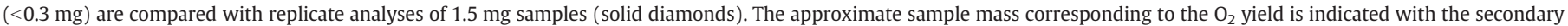
labels.

using the IRMS technique (Miller et al., 1999): the oxygen threeisotopic composition was measured using a Micromass (Wythenshawe, Manchester, UK) PRISM III dual-inlet mass spectrometer. A systematic mass-dependent offset for small samples is also observed in this laboratory (Greenwood et al., 2007). The offset at the Open University appears to be due to isotopic fractionation associated with transfer of the gases in the inlet system, and therefore, again, independent of sample type, allowing a small correction relative to the variations observed, to be applied: $-0.49 \%$ for $\delta^{18} \mathrm{O},-0.23 \%$ for $\delta^{17} \mathrm{O}$.

\section{Results}

Fig. 3 features our $\delta^{18} \mathrm{O}$ and $\delta^{17} \mathrm{O}$ single micrometeorite IRMS data, with data obtained for previous studies by fluorination of composite samples (Clayton et al., 1986) and ion probe data measured on Antarctic

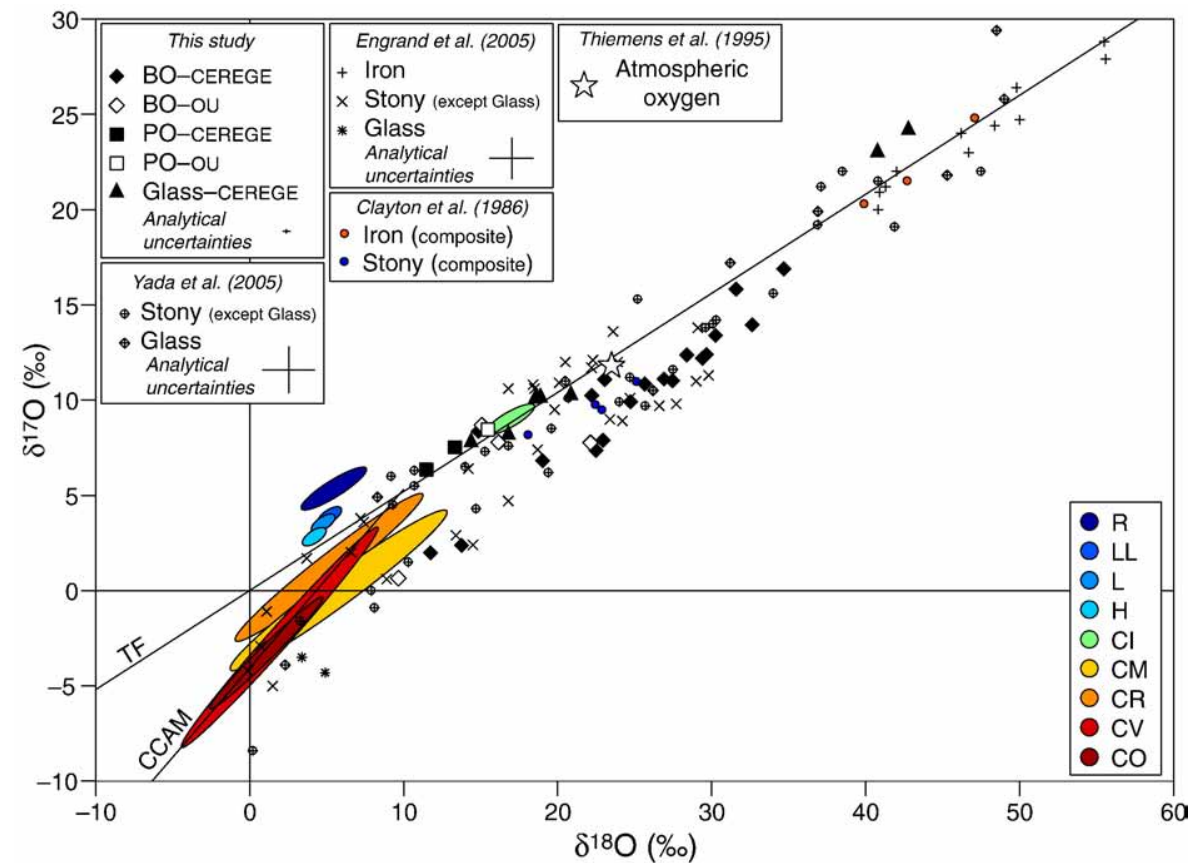

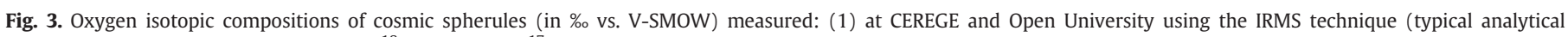

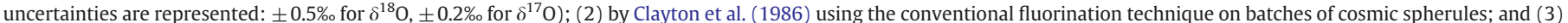

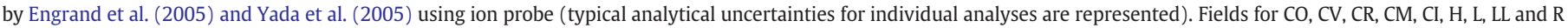

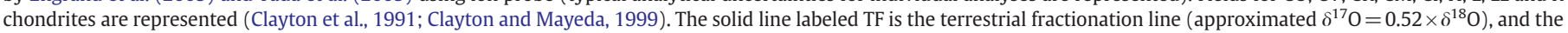
solid line labeled CCAM is the carbonaceous chondrite anhydrous minerals line (approximated $\left.\delta^{17} \mathrm{O}=0.938 \times \delta^{18} \mathrm{O}-4.06\right)(\mathrm{Clayton}$ and Mayeda, 1999). 
Table 1

\begin{tabular}{|c|c|c|c|c|c|c|}
\hline \multirow[b]{2}{*}{ Sample name } & \multirow[b]{2}{*}{ Type } & \multirow[b]{2}{*}{$\begin{array}{l}\text { Mass } \\
(\mu g)\end{array}$} & \multicolumn{4}{|c|}{ Oxygen isotope measurements } \\
\hline & & & Lab. & $\delta^{18} \mathrm{O}$ & $\delta^{17} \mathrm{O}$ & $\Delta^{17} \mathrm{O}$ \\
\hline A1 & BO & 439 & $\mathrm{C}$ & 28.4 & 12.4 & -2.4 \\
\hline A2 & BO & 420 & $\mathrm{C}$ & 22.5 & 7.4 & -4.3 \\
\hline A3 & $\mathrm{BO}$ & 350 & $\mathrm{C}$ & 32.6 & 14.0 & -3.0 \\
\hline A4 & BO & 276 & $\mathrm{C}$ & 19.0 & 6.8 & -3.1 \\
\hline A5 & BO & 501 & $\mathrm{C}$ & 25.7 & 10.8 & -2.5 \\
\hline A6 & $\mathrm{BO}$ & 458 & $\mathrm{C}$ & 30.3 & 13.4 & -2.3 \\
\hline A7 & BO & 262 & $\mathrm{C}$ & 11.8 & 2.0 & -4.1 \\
\hline A8 & $\mathrm{BO}$ & 282 & $\mathrm{C}$ & 27.5 & 11.0 & -3.3 \\
\hline A9 & BO & 660 & $\mathrm{OU}$ & 22.1 & 7.8 & -3.8 \\
\hline A10 & BO & 404 & OU & 9.7 & 0.7 & -4.4 \\
\hline A11 & BO & 556 & C & 29.4 & 12.2 & -3.1 \\
\hline A12 & BO & 690 & C & 22.9 & 7.9 & -4.0 \\
\hline A13 & BO & 386 & C & 24.7 & 9.9 & -2.9 \\
\hline A14 & BO & 528 & C & 26.9 & 11.1 & -2.9 \\
\hline A15 & BO & 330 & C & 13.8 & 2.4 & -4.8 \\
\hline A16 & BO & 445 & C & 29.7 & 12.4 & -3.0 \\
\hline B1 & BO & 395 & C & 31.6 & 15.8 & -0.6 \\
\hline B2 & BO & 590 & C & 34.7 & 16.9 & -1.2 \\
\hline B3 & $\mathrm{V}$ & 444 & C & 16.8 & 8.2 & -0.6 \\
\hline B4 & $\mathrm{V}$ & 559 & C & 20.9 & 10.3 & -0.6 \\
\hline B5 & BO & 466 & $\mathrm{OU}$ & 16.2 & 7.8 & -0.7 \\
\hline B6 & BO & 314 & C & 23.1 & 11.1 & -0.9 \\
\hline B7 & BO & 353 & C & 22.2 & 10.2 & -1.3 \\
\hline C1 & PO & 392 & C & 13.3 & 7.5 & 0.6 \\
\hline C2 & BO & 541 & C & 14.9 & 8.4 & 0.6 \\
\hline C3 & $\mathrm{V}$ & 438 & C & 18.9 & 10.1 & 0.3 \\
\hline C4 & V & 393 & C & 18.6 & 10.1 & 0.4 \\
\hline C5 & $\mathrm{V}$ & 481 & C & 14.4 & 7.8 & 0.3 \\
\hline C6 & PO & 728 & C & 11.5 & 6.4 & 0.4 \\
\hline C7 & BO & 636 & $\mathrm{OU}$ & 15.1 & 8.7 & 0.8 \\
\hline C8 & PO & 877 & OU & 15.5 & 8.5 & 0.4 \\
\hline D1 & V & 302 & C & 42.8 & 24.2 & 1.9 \\
\hline D2 & V & 314 & C & 40.8 & 23.0 & 1.8 \\
\hline
\end{tabular}

Type: $\mathrm{BO}=$ barred olivine; $\mathrm{PO}=$ porphyritic olivine; $\mathrm{V}=$ glassy. Lab.: $\mathrm{C}=\mathrm{CEREGE}$; $\mathrm{OU}=$ Open University. Oxygen isotope ratios are in \% vs. V-SMOW.

CSs (Engrand et al., 2005; Yada et al., 2005) together with bulk isotopic compositions of meteorites (Clayton et al., 1991; Clayton and Mayeda, 1999). Our data covers the spectrum of $\delta^{18} \mathrm{O}$ and $\delta^{17} \mathrm{O}$ values obtained by previous studies on stony CSs, with a much better precision. Furthermore, data obtained in both laboratories are in good agreement. It is possible to roughly distinguish 4 groups of isotopic signatures in our data (Table 1; see Section 4 for a discussion about this grouping).

Group 1 (samples A1-A16, 48\% of the total): most CSs with barred olivine (BO) textures $(16 / 23)$ have $\Delta^{17} \mathrm{O} \approx-3$ to $-5 \%$ and $\delta^{18} \mathrm{O}$ in the $10-30 \%$ range.

Group 2 (samples B1-B7, 21\% of the total): five BO CSs and 2 glass CSs have $\Delta^{17} \mathrm{O} \approx-1 \%$ and $\delta^{18} \mathrm{O}$ in the $15-35 \%$ range.

Group 3 (samples C1-C8, 24\% of the total): two BO CSs, all 3 CSs with porphyritic olivine (PO) texture, and 3 glass CSs have $\Delta^{17} \mathrm{O} \approx 0.4$ to $0.8 \%$ and $\delta^{18} \mathrm{O}$ in the $10-20 \%$ range.

Group 4 (samples D1-D2, 6\% of the total): 2 glass CSs have $\Delta^{17} \mathrm{O} \approx 1.8 \%$ and $\delta^{18} \mathrm{O} \approx 41 \%$, which is near to the value found for three glass CSs in a previous study (Yada et al., 2005).

\section{Discussion}

The isotopic signature of micrometeorites depends on the signature of the parent body, and of two processes: contamination by atmospheric oxygen, and mass-dependent fractionation during atmospheric entry. When micrometeoroids enter the atmosphere, they melt at an altitude of $85-90 \mathrm{~km}$ (in the upper mesosphere), and they are quenched in a few seconds (Love and Brownlee, 1991). When the particle is melted, oxygen is exchanged with the environment. The isotopic signature of atmospheric $\mathrm{O}_{2}$ has been shown to be a constant $\delta^{18} \mathrm{O} \approx 23.5 \%$, $\delta^{17} \mathrm{O} \approx 11.8 \%$, up to an altitude of $60.9 \mathrm{~km}$ (Thiemens et al., 1995). Based on the observation of a downward flux of light $\mathrm{O}$ isotopes in the upper stratosphere and a qualitative modelling (Colegrove et al., 1965), Thiemens et al. (1995) suggested that a source of heavy O isotopes may exist in the upper mesosphere. However, no origin for such an isotopic fractionation can be specified. Therefore, we use the stratospheric isotopic composition $\delta^{18} \mathrm{O} \approx 23.5 \%$, $\delta^{17} \mathrm{O} \approx 11.8 \%$ as a minimally heavy O isotope-enriched composition to represent the oxygen micrometeorites encounter during atmospheric entry. The heating of the particles also causes loss of material by evaporation (Engrand et al., 2005) and

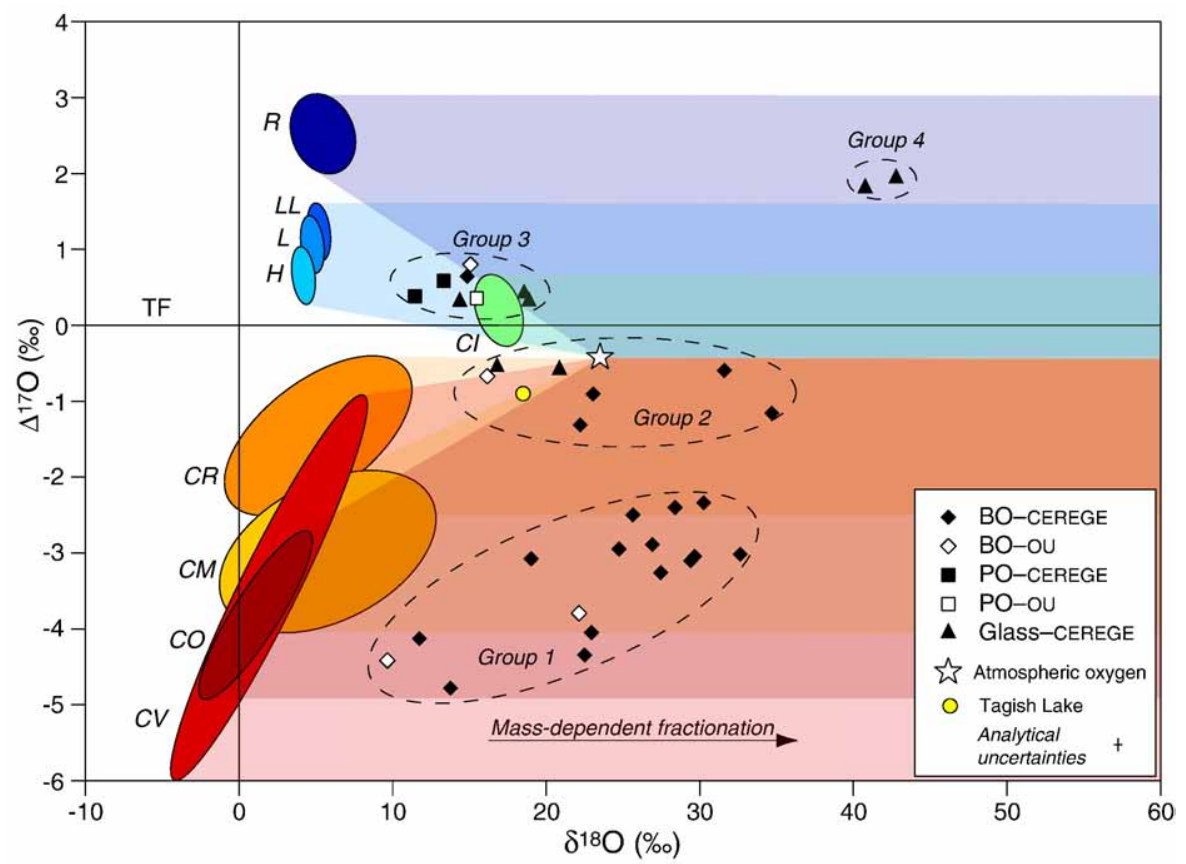

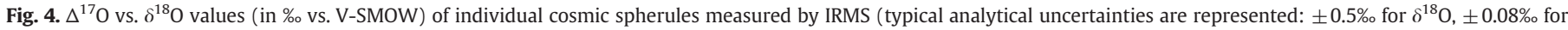

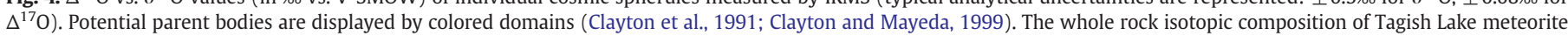
(Brown et al., 2000) is also represented. The range of possible values of $\Delta^{17} \mathrm{O}$ and $\delta^{18} \mathrm{O}$ for a micrometeorite from a given parent body is represented with a shaded area. 
separation of iron-nickel droplets (Genge and Grady, 1998), which induce a mass-dependent fractionation of the oxygen. These processes may have various contributions to the measured isotopic signature, depending on the particle velocity, entry angle, iron-nickel content and mineralogy.

Fig. 4 represents $\Delta^{17} \mathrm{O}$ as a function of $\delta^{18} \mathrm{O}$ for our samples, with possible parent bodies: carbonaceous chondrites $\mathrm{CO}, \mathrm{CV}, \mathrm{CM}, \mathrm{CR}, \mathrm{CI}$; ordinary chondrites H, L, LL; and R chondrites (Clayton et al., 1991; Clayton and Mayeda, 1999). Starting from a parent material, we can define a domain of possible values for the isotopic signature of micrometeorites bounded by a line parallel to the TFL along which mass-dependent fractionation occurs, and a line connecting the value of the parent material to that of atmospheric oxygen, along which pure contamination by terrestrial oxygen occurs.

Iron CSs, derived from particles made entirely of metal grains, provide a direct test of this model as they do not contain oxygen before melting and therefore the oxygen they contain now is derived entirely from the atmosphere. Their $\Delta^{17} \mathrm{O}$ is indeed close to the atmospheric value (Clayton et al., 1986; Engrand et al., 2005), with $\delta^{18} \mathrm{O}$ in the $40-60 \%$ 。 range (Fig. 3). Therefore, the oxygen isotopic signature of CSs is expected to lie between an extraterrestrial endmember composition - that may be a known meteorite group or an unknown parent body - and an "atmospheric entry end-member" that is exemplified by the iron CSs.

CSs from Group 1 and Group 2 appear to be related to carbonaceous chondrites, with the $\mathrm{CO} / \mathrm{CV}$ and $\mathrm{CM} / \mathrm{CR}$ end-members. Although most of these CSs could originate from any type of carbonaceous chondrite, the 5 micrometeorites with $\Delta^{17} \mathrm{O}<-4$ cannot be related to $\mathrm{CM} / \mathrm{CR}$ parent bodies, and have a $\mathrm{CO} / \mathrm{CV}$ chondrite-related parent body. The isotopic composition of the two glass CSs and one BO CS from Group 2 (B5) can only be explained by a CR parent body. Group 2 CSs could also be related to the parent body of the Tagish Lake meteorite (Brown et al., 2000). CSs from Group 1 plot along a line of increasing $\Delta^{17} \mathrm{O}$ with increasing $\delta^{18} \mathrm{O}$, the slope of which reflects the relationship between mixing with atmospheric oxygen and fractionation during atmospheric entry. The differences in mixing/fractionation magnitude within this group are most probably related with the entry parameters of the particles: high-velocity particles and high-entry angle particles encounter more oxygen and are more heated, and should experience more mixing and fractionation. Fig. 5 is an attempt to quantify the degree of mass fractionation compared with mixing with atmospheric oxygen for BO CSs of Group 1 and Group 2 (excluding one outlier: B5): the percentage of mixing, defined between a parent body composition and atmospheric composition, is represented as a function of the maximum fractionation the particle went through. Assuming that Group 1 CSs have a CO/CV parent body, and that Group 2 CSs have a CM/CR parent body, we find that both groups have a similar trend, which indicates that the relative degree of mixing and fractionation is the same. Conversely, assuming that Group 2 CSs have the same parent body as Group 1 CSs would give very different relationships between mixing and fractionation for the two groups. Therefore, the definition of Group 1 and Group 2 based on the isotopic composition is also consistent once similar atmospheric entry effects and different parent bodies are assumed.

The isotopic compositions of CSs from Group 3 are not greatly different from Group 2 in absolute values. However, they are clearly different in terms of parent bodies. Indeed, atmospheric entry processes tend to pull the composition closer to the TFL, but it is impossible for the composition to cross this line. CSs from Group 3 seem to have an ordinary chondrite-related parent body: although glass micrometeorites from this group are closer to the $\mathrm{CI}$ chondrite domain, a CI parent body is not consistent with these results once atmospheric effects are considered. Indeed, the sequence of textures with increasing heating and evaporation of $\mathrm{Fe}: \mathrm{PO}<\mathrm{BO}<$ glass (Taylor et al., 2000) is also found in the increasing $\delta^{18} \mathrm{O}$ (fractionation) and decreasing $\Delta^{17} \mathrm{O}$ (contamination by atmospheric oxygen) for micro-
A
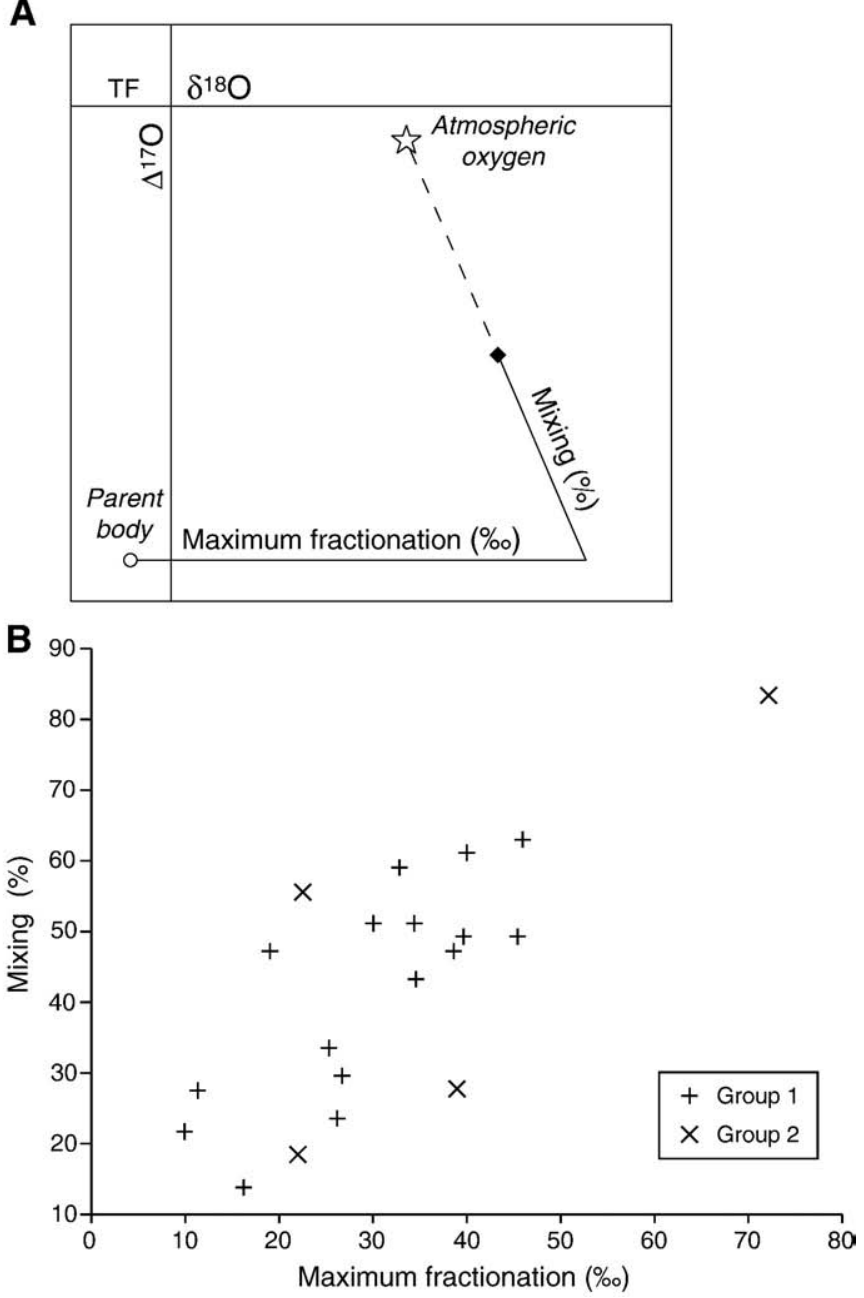

Fig. 5. Quantification of atmospheric entry effects. (A) Definition of "maximum fractionation" and "mixing." (B) Atmospheric entry effects using $\delta^{18} \mathrm{O}=-4 \%, \Delta^{17} \mathrm{O}=$ $-5.5 \%$ as parent body composition for Group $1 \mathrm{CSs}$ and $\delta^{18} \mathrm{O}=0 \%, \Delta^{17} \mathrm{O}=-1.5 \%$ 。 for Group 2. The slopes are $0.01\left(R^{2}=0.61\right)$ for Group 1 and $0.009\left(R^{2}=0.56\right)$ for Group 2.

meteorites of Group 3. This is consistent with PO CSs retaining pristine oxygen isotopic composition in relict grains (Genge et al., 2008).

Fig. 6 presents our data for Group 4 micrometeorites with possible parent bodies. The only known parent material for these glass CSs could be the $\mathrm{R}$ chondrites, or the high $\Delta^{17} \mathrm{O}$ component observed in the magnetites (Choi et al., 1998) and the mesostasis of unequilibrated ordinary chondrites (Franchi et al., 2001). Enrichments in ${ }^{17} \mathrm{O}$ and ${ }^{18} \mathrm{O}$ are known for some atmospheric components (Thiemens et al., 1995) and therefore a possible atmospheric effect in these glass spherules with very high $\delta^{18} \mathrm{O}$ cannot be entirely ruled out. These specimens may also be related to CSs with enrichments in ${ }^{17} \mathrm{O}$ reported by Yada et al. (2005); the data from this study are also represented on Fig. 6. Interestingly, one cryptocrystalline spherule with a very high enrichment in ${ }^{17} \mathrm{O}$ is located on the crystobalite line (CRIL; Bridges et al., 1998) defined by measurements of crystobalites in the mesostases of unequilibrated ordinary chondrite Parnallee. This $\mathrm{CS}$ could be related to the ${ }^{17} \mathrm{O}$ enriched end-member hypothesized to explain this trend. This component could also yield the compositions observed in Group 4 CSs by interaction with the atmosphere during the entry.

Magnetic measurements (Fig. 7) give more insight into the key mineral controlled by heating during atmospheric entry: magnetite. As magnetite is the only significant ferromagnetic mineral in melted micrometeorites (Suavet et al., 2009b), the value of the saturation magnetization $M_{\mathrm{s}}$ is directly proportional to the amount of magnetite 


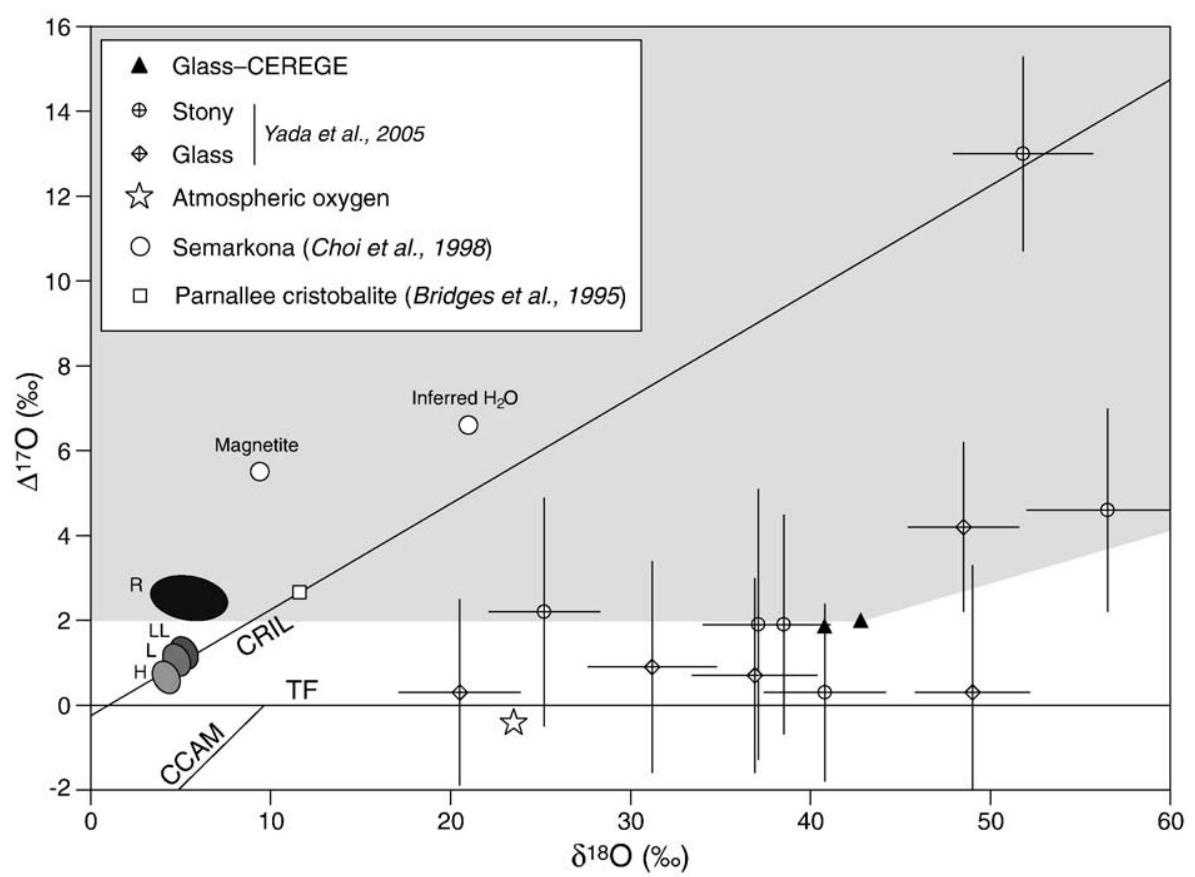

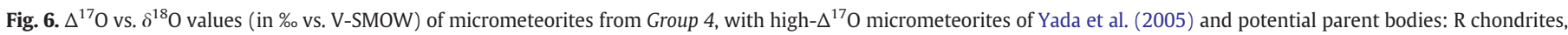

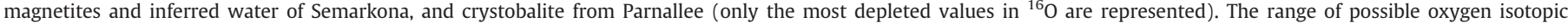
compositions for the parent bodies of Group 4 micrometeorites is represented by the light-grey area.

in the micrometeorite (the magnetite $w t \%$ is $M_{\mathrm{s}} / 0.92$ (Dunlop, 2002)). A trend of higher magnetite content for CSs with higher $\delta^{18} \mathrm{O}$ is visible in Group 2.

The positive correlation of magnetite amount with $\delta^{18} \mathrm{O}$ is consistent with the processes of oxidation by high- $\delta{ }^{18} \mathrm{O}$ atmospheric oxygen and mass-dependent fractionation for particles that experience more heating. Magnetite amount may essentially trace the amount of oxidation of $\mathrm{Fe}^{2+}$ in the melt of olivine composition. Group 1 seems to have a similar trend, although two outliers have uncorrelated high $M_{s}$ values that may indicate presence of magnetite
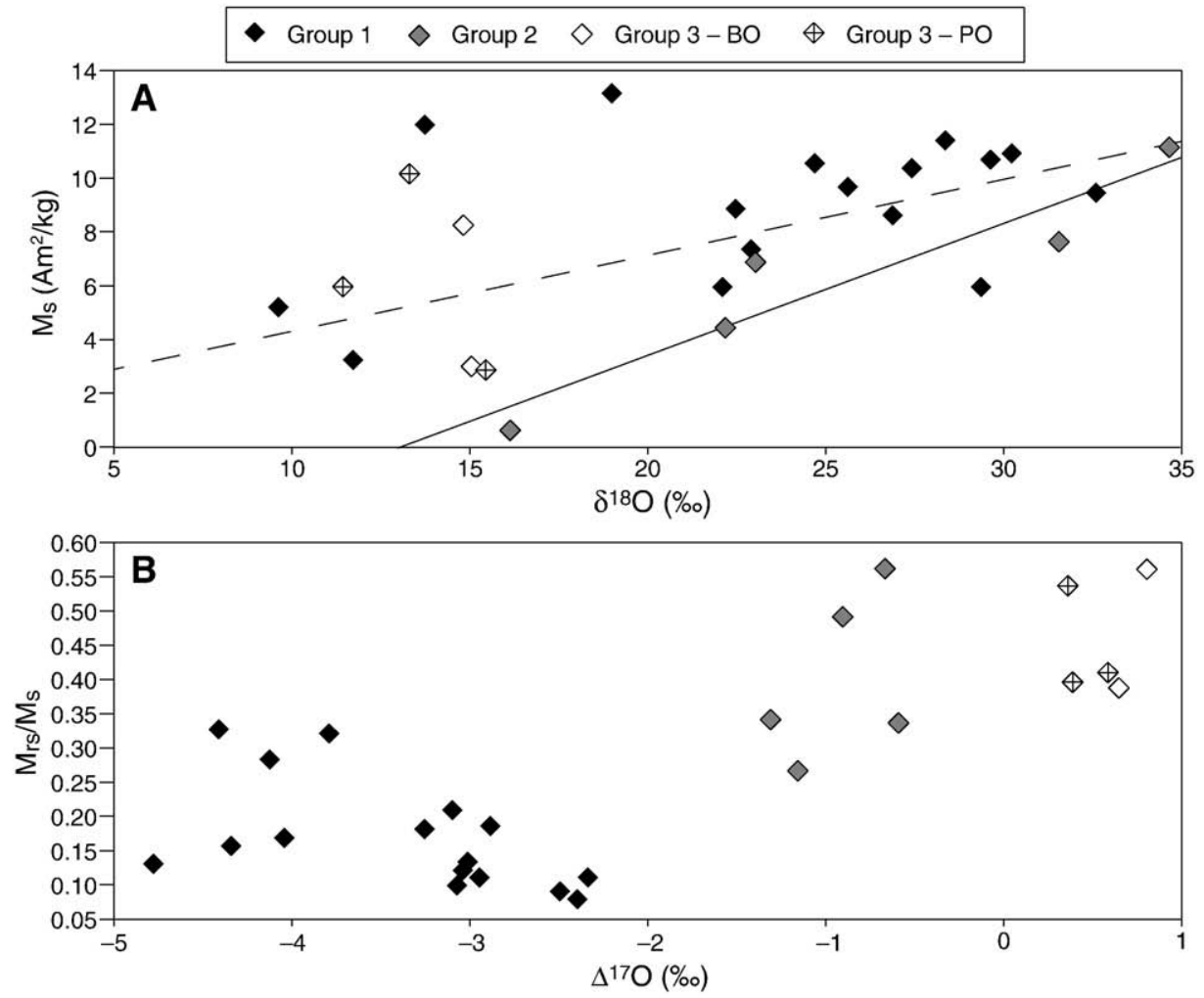

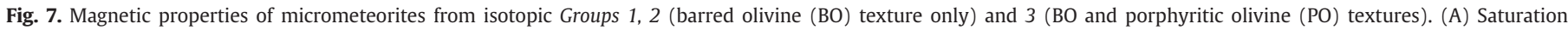

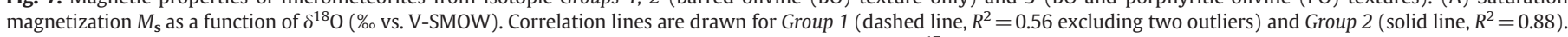
(B) Ratios of saturation remanent magnetization $M_{\mathrm{rs}}$ and saturation magnetization $M_{\mathrm{S}}$ as a function of $\Delta^{17} \mathrm{O}$ (\%。 Vs. V-SMOW). 
before atmospheric entry. Based on the observed correlation, the preatmospheric entry end-member composition can be predicted for $M_{\mathrm{s}}=0$ at $\delta^{18} \mathrm{O} \approx 13 \%$ for Group 2 and $\delta^{18} \mathrm{O} \approx-5$ for Group 1 (if we exclude the two outliers), which is roughly in agreement with the inferred $\mathrm{CM}$ and $\mathrm{CO} / \mathrm{CV}$ carbonaceous chondrite compositions (Clayton and Mayeda, 1999). The value of the ratio of saturation remanent magnetization $M_{\mathrm{rs}}$ and saturation magnetization $M_{\mathrm{s}}$ gives an estimate of the magnetite grain-size (Dunlop, 2002). Higher ratios correspond to smaller grain-size. Micrometeorites from Group 1 seem to have larger magnetite grains than Group 2 and Group 3. As magnetite is formed by oxidation of iron bearing phases, the magnetite grain-size differences probably reflect differences in composition of the parent minerals (especially fayalite mole percent (Fa\%) in olivine), although differences in heating kinetics - as the entry velocity and angle vary for particles of different origins (Love and Brownlee, 1991) - could also cause them. Larger grain sizes are expected for the oxidation of high Fa\% olivine. This is in agreement with the lower Fa\% observed in $\mathrm{H}$ and L chondrites (Group 3) with respect to average carbonaceous chondrites (Group 1).

Our finding of $30 \%$ of micrometeorites above the TFL, while previous studies by ion probe found none (Engrand and Maurette, 1998; Matrajt et al., 2006) or 6\% (Yada et al., 2005), may be related to the lower precision of these previous analyses (e.g. not allowing to distinguish the ordinary chondrite-related samples from the TFL). It could also indicate a higher proportion of ordinary chondrite-related material in our large (diameter $>500 \mu \mathrm{m}$ ) CSs, that may show an intermediate proportion between meteorites (80\% above TFL) and small micrometeorites (0-6\% above TFL). Recent petrogeochemical investigations of coarse grained unmelted micrometeorites suggest that about $20 \%$ of all micrometeorites would be ordinary chondriterelated (Genge et al., 2008), which is in agreement with our results. It has been suggested that the high abundance of $\mathrm{CM} / \mathrm{CR}$ related unmelted micrometeorites may be a result of the dust production mechanisms rather than the abundance of their parent bodies in the main asteroid belt (Genge, 2006). This idea is confirmed by impact destruction experiments (Flynn et al., 2009) on hydrous (CM) and anhydrous (ordinary chondrite) targets: there is an order of magnitude increase of dust production in the $30-300 \mu \mathrm{m}$ size range for the hydrous target. This may explain why previous authors, who studied mainly the $150-250 \mu \mathrm{m}$ size fraction, have concluded for an overwhelming dominance of $\mathrm{CM}$ parent body related micrometeorites while the large (our study) or small (IDPs) fractions may sample different populations of dust particles in Earth-crossing orbits. Our finding of $\mathrm{CO} / \mathrm{CV}$-related cosmic spherules in the $>500 \mu \mathrm{m}$ size fraction is consistent with the study of Genge et al. (2008), who explained the absence of unmelted micrometeorites with affinities to $\mathrm{CO} / \mathrm{CV}$ by the higher eccentricities of their potential asteroidal sources, resulting in a higher entry velocity and a more intense heating during atmospheric entry. Our results could also reflect a variation of the composition of the flux of extraterrestrial materials to the Earth: micrometeorites from the Transantarctic Mountains sample this influx at the hundreds of thousands of years timescale, whereas other studies were made on samples accreted in the last few thousands of years.

\section{Conclusions}

The availability of the TAM micrometeorite collection, and of IRMS for high-precision oxygen isotope measurements, is a great opportunity for the characterization of the extraterrestrial dust flux entering Earth's atmosphere over the million-year time scale (Rochette et al., 2008; Folco et al., 2008, 2009). The discovery of significant numbers of micrometeorites with ordinary chondrite and $\mathrm{CO} / \mathrm{CV}$ carbonaceous chondrite oxygen isotopic compositions is a strong argument against the idea that all micrometeorites derive from carbonaceous chondrite-related parent bodies that are not sampled as meteorites. It supports the claim that ordinary chondrite- and $\mathrm{CO} / \mathrm{CV}$-related asteroids produce dust, and that interplanetary dust in the Earthcrossing orbit partly originates from these objects.

\section{Acknowledgements}

This work was supported by the Italian Programma Nazionale delle Ricerche in Antartide, the French Institut Polaire Paul Emile Victor, the French Institut National des Sciences de l'Univers - Centre National d'Etudes Spatiales Planetology program, the European Union through the Marie Curie Actions - RTNs ORIGINS (project ID: 35519), and by the French Agence Nationale de la Recherche (project ID: ANR-05-JCJC0133). Ian A. Franchi and Richard C. Greenwood were supported by STFC rolling grant. We thank Florence Sylvestre (CEREGE) for additional measurements on small masses of quartz standard; Matthieu Gounelle, Philippe Claeys and Benjamin P. Weiss for their comments during the preparation of this manuscript; and Rick Carlson, Matt Genge and an anonymous reviewer for reviewing this work.

\section{References}

Alexandre, A., Sonzogni, C., Basile, I., Sylvestre, F., Parron, C., Meunier, J.D., Colin, F., 2006. Oxygen isotope analyses of fine silica grains using laser-extraction technique: comparison with oxygen isotope data obtained from ion microprobe analyses and application to quartzite and silcrete cement investigation. Geochim. Cosmochim. Acta 70, 2827-2835.

Bridges, J.C., Franchi, I.A., Hutchinson, R., Sexton, A.S., Pillinger, C.T., 1998. Correlated mineralogy, chemical compositions, oxygen isotopic compositions and size of chondrules. Earth Planet. Sci. 155, 183-196.

Brown, P.G., et al., 2000. The fall, recovery, orbit, and composition of the Tagish Lake Meteorite: a new type of carbonaceous chondrite. Science 290, 320-325. doi:10.1126/science.290.5490.320.

Choi, B.G., McKeegan, K.D., Krot, A.N., Wasson, J.T., 1998. Extreme oxygen-isotopic composition in magnetite from unequilibrated ordinary chondrites. Nature 392, 577-579.

Clayton, R.N., Mayeda, T.K., 1999. Oxygen isotope studies of carbonaceous chondrites. Geochim. Cosmochim. Acta 63, 2089-2104.

Clayton, R.N., Mayeda, T.K., Brownlee, D.E., 1986. Oxygen isotopes in deep-sea spherules. Earth Planet. Sci. Lett. 79, 235-240.

Clayton, R.N., Mayeda, T.K., Olsen, E.J., Goswami, J.N., 1991. Oxygen isotope studies of ordinary chondrites. Geochim. Cosmochim. Acta 55, 2317-2337.

Colegrove, F.D., Hanson, W.B., Johnson, F.S., 1965. Eddy diffusion and oxygen transport in the lower thermosphere. J. Geophys. Res. 70, 4931-4941.

Crespin, J., Alexandre, A., Sylvestre, F., Sonzogni, C., Paillès, C., Garreta, V., 2008. IR laser extraction technique applied to oxygen isotope analysis of small biogenic silica samples. Anal. Chem. 80, 2372-2378.

Dunlop, D.J., 2002. Theory and application of the Day plot (Mrs/Ms vs. Hcr/Hc). 1. Theoretical curves and tests using titanomagnetite data. J. Geophys. Res. 107 (B3). doi:10.1029/2001JB000486

Eiler, J.M., Farley, K.A., Valley, J.W., Stolper, E.M., Hauri, E.H., Craig, H., 1995. Oxygen isotope evidence against bulk recycled sediment in the mantle sources of Pitcairn Island lavas. Nature 377, 138-141. doi:10.1038/377138a0.

Engrand, C., Maurette, M., 1998. Carbonaceous micrometeorites from Antarctica. Meteorit. Planet. Sci. 33, 565-580.

Engrand, C., McKeegan, K.D., Leshin, L.A., Herzog, G.F., Schnabel, C., Nyquist, L.E. Brownlee, D.E., 2005. Isotopic compositions of oxygen, iron, chromium, and nickel in cosmic spherules: toward a better comprehension of atmospheric entry heating effects. Geochim. Cosmochim. Acta 69, 5365-5385.

Flynn, J., Durda, D.D., Minnick, M.A., Strait, M., 2009. Production of cosmic dust by hydrous and anhydrous asteroids: implications for the production of interplanetary dust particles and micrometeorites. Lunar Planet. Sci. LX, \#1164.

Folco, L., Rochette, P., Perchiazzi, N., D'Orazio, M., Laurenzi, M.A., Tiepolo, M., 2008. Microtektites from Victoria Land Transantarctic Mountains. Geology 36. doi:10.1130/ G24528A.1.

Folco, L., D'Orazio, M., Tiepolo, M., Tonarini, S., Ottolini, L., Perchiazzi, N., Rochette, P., Glass, B.P., 2009. Transantarctic Mountain microtektites: geochemical affinity with Australasian microtektites. Geochim. Cosmochim. Acta 73. doi:10.1016/j.gca.2009.03.021.

Franchi, I.A., Wright, I.P., Sexton, A.S., Pillinger, C.T., 1999. The oxygen-isotopic composition of Earth and Mars. Meteorit. Planet. Sci. 34, 657-661.

Franchi, I.A., Baker, L., Bridges, J.C., Wright, I.P., Pillinger, C.T., 2001. Oxygen isotopes and the early solar system. Philos. Trans. R. Soc. A 359, 2019-2035. doi:10.1098/rsta.2001.0894. Genge, M.J., 2006. Igneous rims on micrometeorites. Geochim. Cosmochim. Acta 70, 2603-2621. doi:10.1016/j.gca.2006.02.005.

Genge, M.J., 2008. Koronis asteroid dust in Antarctic ice. Geology 36, 687-690. doi:10.1130/G24493A.1

Genge, M.J. Grady, M.M., 1998. Melted micrometeorites from Antarctic ice with evidence for the separation of immiscible Fe-Ni-S liquids during entry heating. Meteorit. Planet. Sci. 33, 425-434.

Genge, M.J., Engrand, C., Gounelle, M., Taylor, S., 2008. The classification of micrometeorites. Meteorit. Planet. Sci. 43, 497-515. 
Greenwood, R.C., Schmitz, B., Bridges, J.C., Hutchinson, R., Franchi, I.A., 2007. Disruption of the L chondrite parent body: new oxygen isotope evidence from Ordovician relict chromite grains. Earth Planet. Sci. Lett. 262, 204-213.

Gröning, M., 2004. International stable isotope reference materials. In: De Groot, P.A. (Ed.), Handbook of Stable Isotope Analytical Techniques, Volume I, Chapter 40. Elsevier, pp. 874-906.

Jabeen, I., Kusakabe, M., Nagao, K., Nakamura, T., 1998. Oxygen isotope study of Tsukuba chondrite, some HED meteorites and Allende chondrules. Antarct. Meteorite Res. $11,122-135$.

Kusakabe, M., Maruyama, S., Nakamura, T., Yada, T., 2004. $\mathrm{CO}_{2}$ laser-BrF $\mathrm{B}_{5}$ fluorination technique for analysis of oxygen three isotopes of rocks and minerals. J. Mass Spectrom. Soc. Jpn. 52, 205-212.

Love, S.G., Brownlee, D.E., 1991. Heating and thermal transformation of micrometeoroids entering the Earth's atmosphere. Icarus 89, 26-43. doi:10.1016/0019-1035 (91)90085-8.

Matrajt, G., Guan, Y., Leshin, L., Taylor, S., Genge, M., Joswiak, D., Brownlee, D., 2006. Oxygen isotope measurements of bulk unmelted Antarctic micrometeorites. Geochim. Cosmochim. Acta 70, 4007-4018. doi:10.1016/j.gca.2006.05.010.

Mattey, D.P., Macpherson, C.M., 1993. High-precision oxygen isotope analysis of microgram quantities of silicate by laser-fluorination. Chem. Geol. 105, 305-318.

Miller, M.F., Franchi, I.A., Sexton, A.S., Pillinger, C.T., 1999. High precision delta(17)O isotope measurements of oxygen from silicates and other oxides: method and applications. Rapid Commun. Mass Spectrom. 13, 1211-1217.

Rochette, P., Folco, L., Suavet, C., van Ginneken, M., Gattacceca, J., Perchiazzi, N., Braucher, R., Harvey, R.P., 2008. Micrometeorites from the Transantarctic Mountains. Proc. Natl Acad. Sci. USA 105, 18,206-18,211. doi:10.1073/pnas.0806049105.
Rumble III, D., Farquhar, J., Young, E.D., Christensen, C.P., 1997. In situ oxygen isotope analysis with an excimer laser using $\mathrm{F}_{2}$ and $\mathrm{BrF}_{5}$ reagents and $\mathrm{O}_{2}$ gas as analyte. Geochim. Cosmochim. Acta 61, 4229-4234.

Suavet, C., Rochette, P., Kars, M., Gattacceca, J., Folco, L., Harvey, R.P., 2009a. Statistica properties of the Transantarctic Mountains (TAM) micrometeorite collection. Polar Sci. 3, 100-109. doi:10.1016/j.polar.2009.06.003.

Suavet, C., Gattacceca, J., Rochette, P., Perchiazzi, N., Folco, L., Duprat, J., Harvey, R.P., 2009b. Magnetic properties of micrometeorites. J. Geophys. Res. 114, B04102. doi:10.1029/2008JB005831.

Taylor, S., Lever, J.H., Harvey, R.P., 2000. Numbers, types and compositional distribution of an unbiased collection of cosmic spherules. Meteorit. Planet. Sci. 35, 651-666.

Taylor, S., Alexander, C.M.O'.D., Delaney, G., Ma, P., Herzog, G.F., Engrand, C., 2005 Isotopic fractionation of iron, potassium, and oxygen in stony cosmic spherules: implications for heating histories and sources. Geochim. Cosmochim. Acta 69, 2647-2662. doi:10.1016/j.gca.2004.11.027.

Thiemens, M., Jackson, T., Zipf, E., Erdman, P.W., Van Egmond, C., 1995. Carbon dioxide and oxygen isotope anomalies in the mesosphere and stratosphere. Science 270 969-972. doi:10.1126/science.270.5238.969.

Valley, J.W., Kitchen, N., Kohn, M.J., Niendorf, C.R., Spicuzza, M.J., 1995. UWG-2, a garnet standard for oxygen isotope ratios: strategies for high precision and accuracy with laser heating. Geochim. Cosmochim. Acta 59, 5223-5231.

Yada, T., Nakamura, T., Noguchi, T., Matsumoto, N., Kusakabe, M., Hiyagon, H., Ushikubo, T., Sugiura, N., Kojima, H., Takaoka, N., 2005. Oxygen isotopic and chemical compositions of cosmic spherules collected from the Antarctic ice sheet: implications for their precursor materials. Geochim. Cosmochim. Acta 69, 5789-5804. 